\title{
Life Satisfaction and Stress Level among Working and Non- Working Women
}

\author{
Dr. Shashi Kala Singh*
}

\begin{abstract}
The main aim of the present study was to examine the life satisfaction and stress among working and non-working women. A sample of 200 women (100working \&100non-working) was drawn randomly from the population. Life Satisfaction Scale by Alam \& Srivastava (1996) and stress scale by Singh (2004) were used for data collection. Mean, standard deviation, ' $t$ ' test and correlation were the statistics calculated. The results indicated that there was significant difference regarding life satisfaction and stress between working and non-working women. Results revealed that working and non-working women differed significantly on their life satisfaction $(t=5.52)$.Working women were more satisfied with their life, on stress scale nonworking women have higher level stress as compared to working women. A significant negative relationship was found between life satisfaction and stress.
\end{abstract}

Keywords: Life Satisfaction, Stress and Working and Non-Working Women

\section{INTRODUCTION}

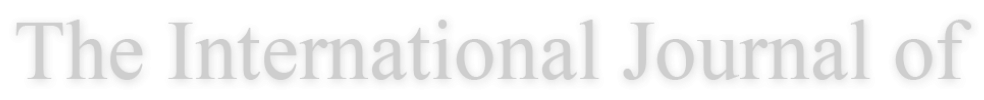

Satisfaction is a state of mind. It is an evaluative appraisal of something. The term refers to both 'contentment' and 'enjoyment'. As such it covers cognitive- as well as affective-appraisals. Satisfaction can be both evanescent and stable through time. Current synonyms for life satisfaction are: 'happiness' and 'subjective well-being'. One advantage in using the term 'lifesatisfaction' rather than the word 'happiness' is that it emphasizes the subjective character of the concept. The word happiness is also used to refer to an objective good; especially by philosophers. The term life-satisfaction has the advantage over the label of 'subjective wellbeing' is that life-satisfaction refers to an overall evaluation of life rather than to current feelings or to specific psychosomatic symptoms.

Growing economies and modern times have witnessed a rise in the number of dual-career families with deleterious effects on Life Satisfaction. In all countries the economic development requires an integration of both male and female labor forces. That is men and women both have to contribute to development process of the country as the labor of women contributes to economic growth and poverty reduction. Traditionally, the major responsibility of women has been perceived to be the maintenance of the family including home and childcare and breadwinning was the main responsibility of men. However, with more and more women entering the workforce and pursuing careers, these clearly defined gender roles were forced to change (Sevim, 2006). Work and family are the two most important aspects in women's lives.

*Associate Professor, Dept. of Psychology, Ranchi University, Ranchi, Zarkhand 


\section{The International Journal of Indian Psychology: Volume: 01 | Issue: 04 | ISSN 2348-5396}

Life satisfaction is defined as an overall, "global assessment" of feelings and attitudes about one's life at a particular point in time according to that individual's "chosen criteria" (Kuskova V. Valentina, 2011). Life satisfaction can create colossal catastrophic consequences for both, the individual as an employee or the individual as a family member. Life satisfaction was defined as an individual's global assessment of his or her life in positive terms (Diener, et.al.,1985).

Life satisfaction is also defined as an overall assessment of feelings and attitudes about one's life at a particular point in time ranging from negative to positive. Subjective life satisfaction is a measure of an individual's perceived level of wellbeing and happiness. Satisfaction with life as a whole must be satisfaction not only with that which is, but also with that which was and that which will be, not only with the present, but also with the past and the future. (Tatarkiewicz, 1976).

Life satisfaction is one factor in the more general construct of subjective wellbeing. Life satisfaction is distinguished from affective appraisal in that it is more cognitively than emotionally driven. Life satisfaction can be assessed specific to a particular domain of life or globally. Satisfaction is a state of mind. It is an evaluative appraisal of something. The term refers to both 'contentment' and 'enjoyment'. As such it covers cognitive-as well as affectiveappraisals. Satisfaction can be both evanescent and stable through time. Life-satisfaction is the degree to which a person positively evaluates the overall quality of his/her life as-a-whole. In other words, how much the person likes the life he/she leads? The concept of life-satisfaction denotes an overall evaluation of life. So the appraisal that life is 'exciting' does not necessarily mean that it is 'satisfying'. There may be too much excitement in life, and too few other qualities. An overall evaluation of life involves all relevant criteria in the mind of the individual: for example, how good one feels, how well expectations are likely to be met and how desirable various factors are deemed to be, etc.

Life satisfaction is the way a person perceives how his or her life has been and how they feel about where it is going in the future. It is a measure of well-being and may be assessed in terms of mood, satisfaction with relations with others and with achieved goals, self-concepts, and selfperceived ability to cope with daily life. It is having a favorable attitude of one's life as a whole rather than their current feelings. Life satisfaction has been measured in relation to economic standing, amount of education, experiences, and the people's residence as well as many other topics.

Life satisfaction is defined as having a favorable attitude towards one's life as a whole. Life satisfaction is defined as having a favorable attitude towards one's life as a whole. The vast majority of studies investigating life satisfaction have been survey based. Life satisfaction can reflect experiences that have affected a person in a positive way. These experiences have the ability to motivate people to pursue and reach their goals.

Life satisfaction is often considered a desirable goal in and of itself stemming from the Aristotelian ethical model, eudemonism, (from eudemonia, the Greek word for happiness) where correct actions lead to individual well-being with happiness representing the supreme good. Stress has been defined both as a non specific adaptive response of the body to any demand and an internal and external stimulus. Stress can be said to involve three major conceptual domains: sources of stress, moderators of stress and the manifestations of stress (Pearlin et al., 1981). We live in stressful times. We are holding down two or more jobs. We are putting up with heavy job 


\section{The International Journal of Indian Psychology: Volume: 01 | Issue: 04 | ISSN 2348-5396}

loads and unreasonable demands. We are swallowing outrage and frustration with unfair situations and irrational superiors because we cannot afford to be laid off or fired.

Women in India have come a long way after independence. From just a skilled homemaker, women today have acquired skills and capabilities of not just being a homemaker but being at par with their male counterparts. This is the new generation of women, who wants to pursue their dream career. But this life is not a bed of roses for all. While there is little consensus among psychologists about the exact definition of stress, it is agreed that stress results when demands placed on an organism cause unusual physical, psychological, or emotional responses. In humans, stress originates from a multitude of sources and causes a wide variety of responses, both positive and negative.

Indian families are undergoing rapid changes due to the increased pace of urbanization and modernization. Indian women belonging to all classes have entered into paid occupations. At the present time, Indian women's exposure to educational opportunities is substantially higher than it was some decades ago, especially in the urban setting. This has opened new vistas, increased awareness and raised aspirations of personal growth. This, along with economic pressure, has been instrumental in influencing women's decision to enter the work force. Most studies of employed married women in India have reported economic need as being the primary reason given for working. One of the most frequently faced psychological problems of recent years is stress and stress related illnesses. Due to an ever changing world, everybody is affected by stress regardless of age, gender, profession, social or economic status. Because of these rapid changes, people live most of their lives under stress. Therefore, the notion of stress has become a widely recognized problem in all aspects of life.

Work-life balance is the maintenance of a balance between responsibilities at work and at home. Work and family have increasingly become antagonist spheres, equally greedy of energy and time and responsible for work-family conflict. We know that stress paralyses the human life on account of which it is difficult for people suffering of stress to live the normal life. Life satisfaction and stress are interrelated with each other. A number of researchers in the specific field have been conducted to measure the level of life satisfaction and stress among working and non working women.

\section{REVIEW OF LITERATURE}

Currently, the literature suggests that personality play a significant role in whether a woman will judge her life to be satisfying. However, proximal environmental factors can influence life satisfaction judgments in the short term. Chipper field and Havens (2001) conducted study to examine life satisfaction among individuals who had undergone a transition in marital status and those whose marital status remained stable over 7- year period. Among those individuals whose marital status remained stable over the 7 years, women's life satisfaction declined and men's remained constant. Among those who experienced a transition- in particular, the loss of spouse a decline in life satisfaction was found for both men and women decline being more predominant for men. In addition, men's life satisfaction increased over the 7 years period if they gained a spouse, whereas the same was not true for women.

Generally, these findings imply that the relationship between marital status transitions or stability differs for men and women. Saundra and Hughey (2003) conducted a study on life satisfaction. In this study, 147 African American women from six states were asked to complete the Adult 


\section{The International Journal of Indian Psychology: Volume: 01 | Issue: 04 | ISSN 2348-5396}

Life Satisfaction Scale and the Black Women's Spirituality/Religiosity Measure (BWSRM). Although no significant difference was found among the ratings of life satisfaction and spirituality with respect to age or educational level, the women reported higher levels of religiosity than spirituality, which correlates significantly with life satisfaction. Kousha and Moheen (2004) explored life satisfaction among unmarried Iranian women in urban areas. A series of path analysis and cross tabulations suggest that for married women life satisfactions directly linked to their satisfaction with marriage, employment and their leisure experiences. For women hours satisfaction and job satisfaction indicate that women prefer part-time jobs irrespective of whether these are small or large.

In contrast, female life satisfaction is virtually unaffected by hours of work. Women without children do not care about their hours of work at all, while women with children are significantly happier if they have a job regardless of how many hours it entails. (Ayres \& Malouff, 2007) have also highlighted the importance of a brief problem-solving training in the workplace that can increase problem-solving skills and problem solving self-efficacy in the course of improving positive effect, job satisfaction, and life satisfaction. Moving away from work impacts on life satisfaction, (Perrone et.al.2007) found that satisfaction with work and marriage was significantly related to life satisfaction. (Schaer, 2008) also stressed on Couples Coping Enhancement Training to increase dyadic competencies which can have positive effects on the general well-being, life satisfaction and other workplace variables like less burnout and less work stress.

According to Northern Territory Government report(2003) workplace stress is the result of the interaction between a person and their work environment. Forth person it is the awareness of not being able to cope with the demands of their work environment, with an associated negative emotional response. European Foundation for the Improvement of Living and Working Conditions (2007) has carried out the study on work related stress.

According to its report work-related stress is a pattern of reactions that occurs when workers are presented with work demands that are not matched to their knowledge, skills or abilities, and which challenge their ability to cope. Park (2007), in their study of work place and job performance, found that negative implications of work stress are recognized as a challenge to both employers and workers, with women, youth, shift, part-time, and non white collar workers being more likely to have high-strain jobs.

\section{HYPOTHESES}

1. Working and non- working women will differ significantly with regard to their life satisfaction.

2. Working and non- working women will differ significantly with regard to their stress level.

3. Life satisfaction and stress were interred related.

\section{SAMPLE}

The sample was drawn from working and non- working women of Ranchi.Thus100 working (who were teacher in the Govt. schools)and 100 non-working women (housewives)were drawn randomly. Working women were highly qualified. Age range of women was 26- 40 years. 


\section{INSTRUMENT}

Life Satisfaction Scale - It was developed and standardized by Alam and Srivastava (1996). The test consist of 60 items of yes/no type. Yes indicate the satisfaction. Higher scores show higher satisfaction level. The range of age was between 18 to 40 years. Testretest reliability of the test was found to be .84 and Validity is .74.

Stress Scale- It was developed by Singh (2004). The range of age was between 16 to 50 years. Test-retest reliability of the test was found to be .82 and Validity is .61. Higher scores show higher stress level.

\section{PROCEDURE OF DATA COLLECTION}

Data collection was done using random sampling. Purpose of the study was made clear to the participants. The general instructions were given to participants to complete the inventories. Help was provided to the participants in case they found any of the items difficult to comprehend. Filled questionnaires were collected from participants for statistical analysis of data.

\section{STATISTICAL ANALYSIS}

In the present study Mean, SDs, t-test and r- test was applied for statistical analysis of data.

\section{RESULTS AND DISCUSSION}

The main aim of present study was examined of life satisfaction and stress among working and non-working women. The " $t$ " test method was used to analysis data. Results discussions of present study are as under:

Table -1: Means, SDs and " $t$ " value of Working and Non-Working Women on Life Satisfaction

\begin{tabular}{|l|c|c|c|c|c|}
\hline \multicolumn{1}{|c|}{ Groups } & N & Means & SDs & t & P value \\
\cline { 1 - 5 } Working women & 100 & 51.87 & 18.79 & 5.52 & 0.01 \\
\hline Non-working women & 100 & 39.49 & 12.39 & & \\
\hline
\end{tabular}

The result from table -1 , show that there is significant difference between working and nonworking women for life satisfaction. The working woman received higher mean score 51.87as compared to the non-working woman39.49. The standard deviation score of working woman received 18.79and the non-working woman received12.39. So we can say that working woman have higher level of life satisfaction than the non-working woman. The " $t$ " value of life satisfaction is 5.52. There is significant difference between working and working woman. It means hypothesis was supported. Working women were more satisfied with their life. They get salary, earn money, so they can fulfill their needs. They support their family and husband. Working women do not depend upon their husband or family, economically they were independent. For this reason they get satisfaction in life. They perceived their life to be secure. They feel comfortable with their life situations. On the other hand the non-working women are less satisfied with their lives. They underestimate in front of working women. Similar result was found by Bhatt (2013). 
The International Journal of Indian Psychology: Volume: 01 | Issue: 04 | ISSN 2348-5396

Figure 1 - Mean value of Working and Non-Working Women on Life Satisfaction

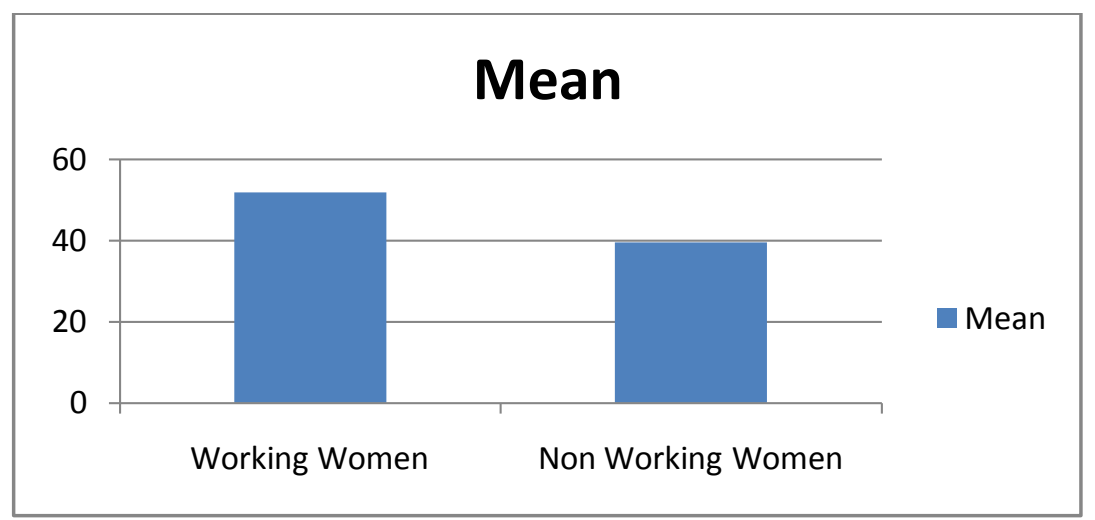

Table-2: Means, SDs and "t" value of working and non-working women on stress

\begin{tabular}{|l|c|c|c|c|c|}
\hline \multicolumn{1}{|c|}{ Groups } & N & Means & SDs & t & P value \\
\cline { 1 - 5 } Working women & 100 & 21.85 & 10.39 & \multirow{2}{*}{7.21} & \multirow{2}{*}{0.01} \\
\cline { 1 - 5 } Non-working women $^{\mathrm{M}}$ & 100 & 34.26 & 13.79 & & \\
\hline
\end{tabular}

According to table-2 the mean scores of non-working women were higher 34.26 as compared to working women 21.85 . This is indicative of the fact that non-working women were facing more stress than working women. Hence, it confirmed the hypothesis which states that "Working and non- working women will differ significantly with regard to their stress level". High stress among non-working women is due to the fact that non-working women occupy multiple roles which are inconsistent and create conflicting situations. Our society still demands the traditional roles of women as homemaker.

Figure 2 - Mean value of Working and Non-Working Women on Stress

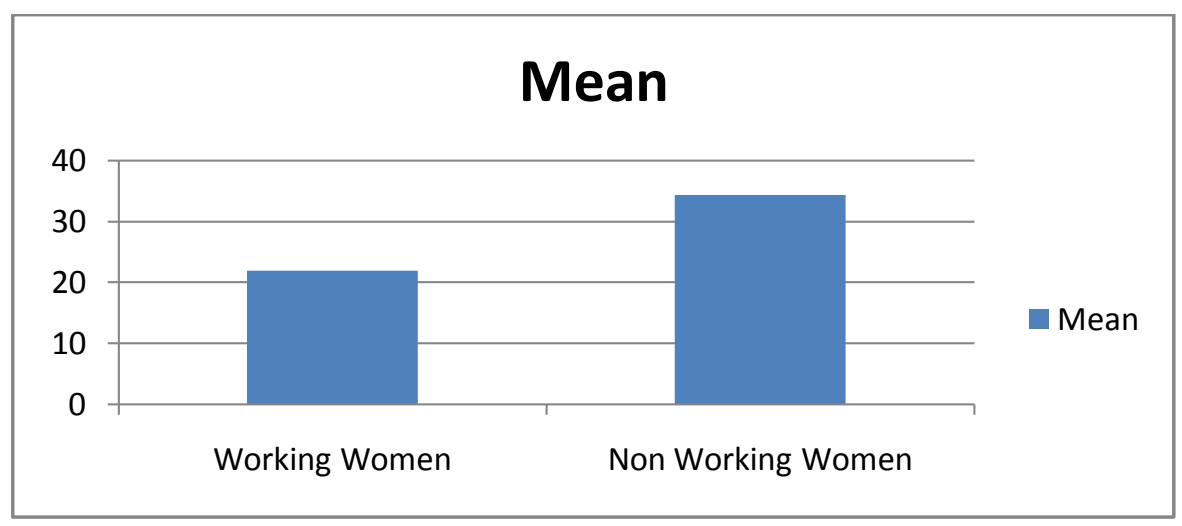

Table-3 - Correlation coefficients of life satisfaction and stress $(\mathrm{N}=200)$

\begin{tabular}{|c|c|c|}
\hline & Stress & P value \\
\hline Life Satisfaction & -0.3125341 & 0.01 \\
\hline
\end{tabular}

(C) 2014 www.ijip.in

July-September 2014

$126 \mid \mathrm{P}$ a g e 


\section{The International Journal of Indian Psychology: Volume: 01 | Issue: 04 | ISSN 2348-5396}

According to above table there was a negative correlation between stress and life satisfaction. This correlation showed that as long as the stress levels increase their life satisfaction level decreases. This showed that stress have a meaningful negative effect on life satisfaction. Those persons who were satisfied with there life, they were have less stress in their life. Azzem \& Ozdevecioglu (2013) were found similar result. Thus, our hypothesis was proved.

\section{REFERENCES:}

1. Ayres Jody \& Malouff M. John. (2007). Problem-solving training to help workers increase Positive effect, Job satisfaction, and Life satisfaction. European Journal of Work \& Organizational Psychology, 16 (3):279 - 294.

2. Azzem, O\&Ozdevecioglu, M. (2013).The effects of occupational stress on burnout and life satisfaction: a study in accountants. Quality \& Quantity. 47(5): 2785-2798.

3. Bhatt, B. (2013).Effect of Employment on Life Satisfaction of Working and Non working women. Acme International Journal of Multidisciplinary Research.1 (1):69 - 73.

4. Chipper field, J.G, \& Havens, B. (2001).Gender Differences in the Relationships between Marital Status Transitions and Life Satisfaction in Later Life. Journal of Marriage and the Family, 12 (3): 176-186.

5. Diener, Ed, Emmons, Robert A., Larsen, Randy J. \& Griffin, Sharon, (1985).The Satisfaction with Life Scale.Journal of Personality Assessment.49(1), 71 - 75.

6. Kousha, M, \& Moheen, N. (2004). Predictors of Life Satisfaction among Urban Iranian Women: An Exploratory Analysis. Journal of Social Indicators Research, 40(3): 320-357.

7. Kuskova V. Valentina (2011). A Longitudinal Analysis of the Relationship between Life Satisfaction and Employee Volunteerism. Academy of Management Proceedings, 10.5464.

8. Managing Stress in the Workplace (2003).NT Work Safe, Department of Employment, Education and Training, Northern Territory Government, 1- 20.

9. Palmore, E, \& Liukart, C. (1972).Health and social factor related to life satisfaction. Journal of Health and Social Behavior.13:68-80.

10. Park, J. (2007). 'Work place and job performance', Perspectives Statistics Canada Catalogue no. 75-001-XIE, 1-13.

11. Peralin, Leonard I., Morton A.Lieberman, Elizabeth G.Menaghan, \& Joseph T Mullan. (1981)."The Stress Process". Journal of Health and Social Behavior.22:337 - 356.

12. Perrone, Kristin M.; Webb, L. Kay; Jackson, Z. Vance.(2007). Relationships between Parental Attachment, Work and Family Roles, and Life Satisfaction.Career Development Quarterly, 55(3):237-248. 
The International Journal of Indian Psychology: Volume: 01 | Issue: 04 | ISSN 2348-5396

13. Saundra, H.S, \& Hughey, A.W. (2003). African American Women at Mid life: The Relationship between Spirituality and life Satisfaction. Journal of African American Women, 18(2): 133-147.

14. Schaer, M. (2008). Balancing Work and Relationship: Couples Coping Enhancement Training (CCET) in the Workplace. Applied Psychology: An International Review, 57: 71-89.

15. Sevim, S.A. (2006). Religious tendency and gender roles: Predictors of the attitudes toward women's work roles. Soc. Behav. Personal. Intl. J. 34: 77- 86.

16. Tatarkiewicz, W. (1976).“Happiness and Time.’Philosophy and Phenomenological Research 27.1-10.

17. Work-related stress, (2007). European Foundation for the Improvement of Living and Working Conditions.1-33.

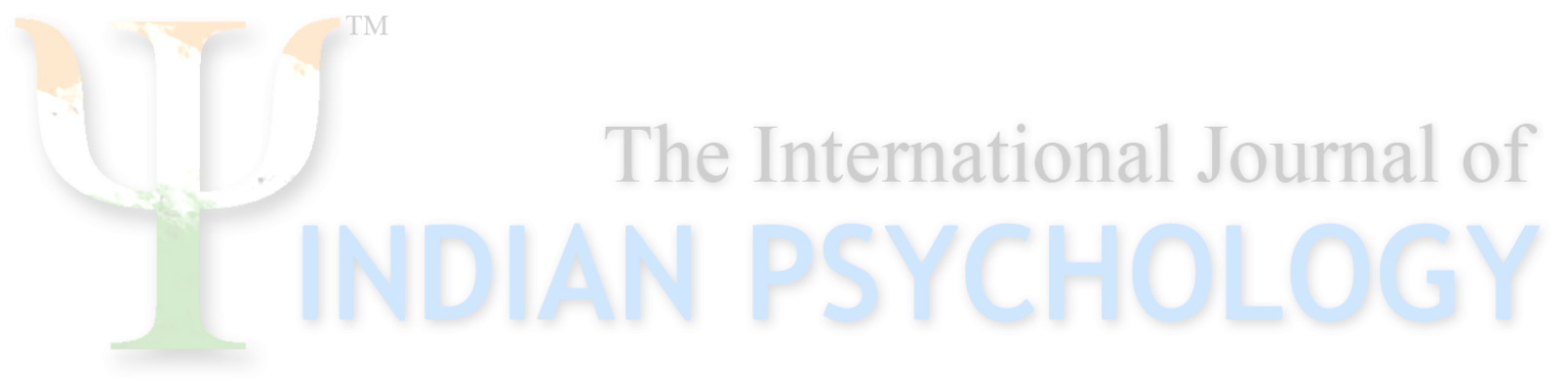

